\title{
Complex array of endobionts in Petalomonas sphagnophila, a large heterotrophic euglenid protist from Sphagnum-dominated peatlands
}

\author{
Eunsoo Kim ${ }^{1}$, Jong Soo Park ${ }^{2}$, Alastair GB Simpson ${ }^{2}$, Shigeru Matsunaga ${ }^{3}$, \\ Masakatsu Watanabe ${ }^{3}$, Akio Murakami ${ }^{4}$, Katrin Sommerfeld ${ }^{1}$, Naoko T Onodera ${ }^{1}$ \\ and John M Archibald ${ }^{1}$ \\ ${ }^{1}$ Department of Biochemistry and Molecular Biology, Canadian Institute for Advanced Research, Program in \\ Integrated Microbial Biodiversity, Dalhousie University, Halifax, NS, Canada; ${ }^{2}$ Department of Biology, \\ Canadian Institute for Advanced Research, Program in Integrated Microbial Biodiversity, Dalhousie \\ University, Halifax, NS, Canada; ${ }^{3}$ Department of Photoscience, Graduate University for Advanced Sciences, \\ Hayama, Japan and ${ }^{4}$ Kobe University Research Center for Inland Seas, Awaji, Japan
}

\begin{abstract}
Petalomonas sphagnophila is a poorly studied plastid-lacking euglenid flagellate living in Sphagnum-dominated peatlands. Here we present a broad-ranging microscopic, molecular and microspectrophotometric analysis of uncultured $P$. sphagnophila collected from four field locations in Nova Scotia, Canada. Consistent with its morphological characteristics, 18S ribosomal DNA (rDNA) phylogenies indicate that $P$. sphagnophila is specifically related to Petalomonas cantuscygni, the only other Petalomonas species sequenced to date. One of the peculiar characteristics of $P$. sphagnophila is the presence of several green-pigmented particles $\sim 5 \mu \mathrm{m}$ in diameter in its cytoplasm, which a previously published study suggested to be cyanobacterial endosymbionts. New data presented here, however, suggest that the green intracellular body may not be a cyanobacterium but rather an uncharacterized prokaryote yet to be identified by molecular sequencing. 16S rDNA library sequencing and fluorescence in situ hybridizations show that $P$. sphagnophila also harbors several other endobionts, including bacteria that represent five novel genus-level groups (one firmicute and four different proteobacteria). 16S rDNA phylogenies suggest that three of these endobionts are related to obligate intracellular bacteria such as Rickettsiales and Coxiella, while the others are related to the Daphnia pathogen Spirobacillus cienkowskii or belong to the Thermoactinomycetaceae. TEM, 16S rDNA library sequencing and a battery of PCR experiments show that the presence of the five $P$. sphagnophila endobionts varies markedly among the four geographic collections and even among individuals collected from the same location but at different time points. Our study adds significantly to the growing evidence for complex and dynamic protist-bacterial associations in nature.
\end{abstract}

The ISME Journal (2010) 4, 1108-1120; doi:10.1038/ismej.2010.40; published online 8 April 2010

Subject Category: microbe-microbe and microbe-host interactions

Keywords: endosymbiosis; endobionts; euglenids; peatlands; Petalomonas; symbiosis

\section{Introduction}

Endosymbiosis can be broadly defined as a state in which one or more organisms live inside the cells of an unrelated host organism. Such associations may be beneficial, harmful or neutral to the host (Werren et al., 2008). Numerous obligate or facultative endobiotic (or endosymbiotic) prokaryotes have

Correspondence: Dr E Kim and Professor JM Archibald, Department of Biochemistry and Molecular Biology, Canadian Institute for Advanced Research, Program in Integrated Microbial Biodiversity, Dalhousie University, Sir Charles Tupper Medical Building, Halifax, NS, Canada B3H 1X5. E-mail: eunsookim@ dal.ca or jmarchib@dal.ca

Received 24 December 2009; revised 1 March 2010; accepted 3 March 2010; published online 8 April 2010 been shown to partake in intimate associations with eukaryotes of diverse evolutionary origin (Dubilier et al., 2008; Moya et al., 2008). For example, the sharpshooter Homalodisca vitripennis, a xylem sap-feeding insect, carries two obligate bacterial endobionts, Baumannia cicadellinicola and Sulcia muelleri, which complement the insect's nutrientdeficient diet (Moya et al., 2008). Some plants, especially legumes, harbor facultative endobiotic bacteria such as Rhizobium that provide fixed nitrogen to their plant hosts (Parniske, 2000; Rasolomampianina et al., 2005). Although such endobiotic prokaryotes have a significant effect on the biochemistry, physiology, development, ecology and evolution of their host eukaryotes, most studies have focused on animal and plant hosts. Far less is 
known about protist-bacterial associations, with the exception of those involving ciliates and a few amoebozoan taxa (Moya et al., 2008).

Among protists, the intracellular symbionts of ciliates have been most intensely studied; about 200 species of ciliates are known to harbor bacterial or archaeal endobionts in various cellular compartments, including the cytoplasm, nucleus, perinuclear space and even mitochondria (Fokin et al., 2003). Parasitic Holospora bacteria occur in the macro- or micronuclei of Paramecium ciliates, whereas various methanogens are known to exist in tight association with the hydrogenosomes of anaerobic ciliates for hydrogen-based syntrophy (Fenchel and Finlay, 1991; Fokin, 2004). The amoebozoan Acanthamoeba is also known to harbor a number of facultative and obligate bacterial endobionts (Horn and Wagner, 2004). For instance, the human bacterial pathogen Legionella pneumophila propagates inside Acanthamoeba and other amoebozoans; this pre-incubation process seems to significantly enhance the ability of $L$. pneumophila to infect its human host (Swanson and Hammer, 2000). In addition, strains of Acanthamoeba host a number of obligate intracellular bacteria, all of which can be assigned to one of four major lineages, the Alphaproteobacteria, Betaproteobacteria, Bacteroidetes and Chlamydiae (Horn and Wagner, 2004; SchmitzEsser et al., 2008). Most studies of protist-bacterial interactions are based on laboratory culture techniques, the process of which allows the growth of only a small number of select organisms. Consequently, even in the case of ciliates and Acanthamoeba, information on how these microbes associate with one another under natural conditions is scarce (Fokin, 2004; Schmitz-Esser et al., 2008).

The euglenids are a morphologically diverse and ecologically significant group of free-living aquatic flagellates, the best-known examples of which are photosynthetic members of the genus Euglena, which harbor plastids of green algal origin (Kim and Archibald, 2009). However, there is a substantial diversity (several genera) of euglenids that lack plastids (Leedale and Vickerman, 2000). Petalomonas sphagnophila is one such plastid-lacking euglenid that nevertheless appears to harbor Synechocystis-like cyanobacteria in its cytoplasm (Schnepf et al., 2002). As its name suggests, $P$. sphagnophila lives and thrives in Sphagnumdominated peatlands (Schnepf et al., 2002), which are important ecosystems where one-third of global soil carbon, 270-370 Gt, is stored (Gorham, 1991; Turunen et al., 2002). Despite the fact that peatlands have an important role in the global carbon cycle and have significant implications for climate change by sequestering $\mathrm{CO}_{2}$ and emitting large amounts of methane $\left(\mathrm{CH}_{4}\right)$ (Gorham, 1991; Wieder and Vitt, 2006), the diversity of peatland microorganisms, their interactions with one another and the biochemical processes they perform are poorly understood.
In this study, we characterized the poorly studied peatland protist $P$. sphagnophila by light and electron microscopy, microspectrophotometric analysis, molecular sequencing and fluorescence in situ hybridization (FISH). We show that its pigmented endobiont is probably not a cyanobacterium, contrary to what was originally proposed by Schnepf et al. (2002). We found that P. sphagnophila harbors additional prokaryotic endobionts, including five novel bacteria. Our studies of several geographic and temporal collections show how P. sphagnophila associates with these endobionts under natural conditions.

\section{Materials and methods}

\section{Sampling sites}

Samples were collected from four Sphagnumdominated peatlands in Nova Scotia, Canada (Supplementary Figure S1). The first was Lizard Lake $\left(44.84^{\circ} \mathrm{N}, 63.62^{\circ} \mathrm{W}\right)$, which is a raised ombrotrophic (that is, receiving water and nutrient supply from precipitation and airborne dust) bog about $20 \mathrm{~km}$ away from the ocean. Lizard Lake is surrounded by a Sphagnum mat about $10 \mathrm{~m}$ in width. The second peatland is located within Duncan's Cove $\left(44.49^{\circ} \mathrm{N}, 63.53^{\circ} \mathrm{W}\right)$, less than $1 \mathrm{~km}$ from the ocean. This site is influenced by sea spray, which is rich in $\mathrm{Mg}, \mathrm{Na}$ and $\mathrm{Cl}$ (Rydin and Jeglum, 2006). The third site is located in Harrietsfield, Nova Scotia $\left(44.59^{\circ} \mathrm{N}, 63.64^{\circ} \mathrm{W}\right)$, which is $7 \mathrm{~km}$ away from the ocean. This site is less than $10 \mathrm{~m}$ from a highway that receives road salt during the winter (road salt runoff as well as marine aerosols can greatly influence the water chemistry of peatlands; Pugh et al., 1996). The fourth site is located on the top of French Mountain on the Cabot Trail, Cape Breton Island $\left(46.74^{\circ} \mathrm{N}, 60.83^{\circ} \mathrm{W}\right)$. $P$. sphagnophila was abundant in samples that were collected within the floating Sphagnum mat area approximately 3$10 \mathrm{~cm}$ below the water surface, where the Sphagnum shoots die and initial decomposition of peat occurs (Rydin and Jeglum, 2006). Samples were collected periodically from May through December when bogs were not frozen; most samples were taken in August and September of 2008 and 2009. The samples were kept at room temperature in plastic containers with little or no air exchange. All the samples had a $\mathrm{pH}$ between 4 and 5 .

\section{PCR, cloning and sequencing}

Attempts to cultivate P. sphagnophila have thus far not been successful. Therefore, individual cells were collected using a finely drawn pipette for DNA extraction. Cells were washed at least 20 times in sterile water drops to remove any particles observable under $\times 400$ magnification, and 8-200 cells were collected in $0.5-\mathrm{ml}$ tubes and kept at $-20^{\circ} \mathrm{C}$. The cells were lysed by two freeze-thaw 
1110

cycles and/or incubation with proteinase-K (final concentration of $1 \mathrm{mg} \mathrm{ml}^{-1}$ ) and sodium dodecyl sulfate (final concentration of 1\%) in TES buffer (100 mM TRIS, $10 \mathrm{mM}$ EDTA, $100 \mathrm{mM} \mathrm{NaCl} \mathrm{(pH} \mathrm{8);}$ final concentration) for $1-3 \mathrm{~h}$ at $37^{\circ} \mathrm{C}$. DNA was extracted by phenol/chloroform and ethanol precipitation.

$18 \mathrm{~S}$ ribosomal DNA (rDNA) sequences were PCRamplified from three geographic collections of $P$. sphagnophila using the following primer set: forward primer (5'-CTGGTTGATCCTGCCAGTWGT-3') and reverse primer $\left(5^{\prime}\right.$-TGATCCTTCYGCAGGTT CACC- $\left.3^{\prime}\right)$. To amplify $16 \mathrm{~S}$ rDNA sequences from $P$. sphagnophila endobionts, various 'universal' and group-specific PCR primers were used (Supplementary Table S1). Most of these PCR primers have been used successfully in earlier studies and we therefore based our PCR conditions on those described previously (for example, reference Nubel et al., 1997; Muhling et al., 2008). The PCR reactions were performed using TaKaRa Ex Taq (RR001A; TaKaRa Bio Inc., Otsu, Japan) or Platinum Taq (10966-018; Invitrogen, Carlsbad, CA, USA). The amplified products were gel-purified and cloned into a pGEM-T Easy Vector (A1360; Promega, Madison, WI, USA). A total of 3-30 clones per band were sequenced using a Beckman Coulter CEQ8000 capillary DNA sequencer (Beckman Coulter, Brea, CA, USA). In sum, 14 16S rDNA libraries were generated, using 'universal' bacterial primers, from four geographic collections (Supplementary Table S2). Newly obtained sequences were deposited in the GenBank database under the accession numbers GU477295-GU477321.

\section{Molecular phylogeny}

Newly obtained $18 \mathrm{~S}$ and $16 \mathrm{~S}$ rDNA sequences were manually assembled and aligned to sequences obtained from GenBank using MacClade version 4.08 (Maddison and Maddison, 2001). Naoji Yubuki provided a euglenozoan 18S rDNA sequence alignment used in a previous study (Yubuki et al., 2009), to which new sequences of $P$. sphagnophila were added manually. Ambiguous sites and longbranched sequences were excluded, leaving a total of 1068 sites and 33 taxa for analysis for the $18 \mathrm{~S}$ rDNA alignment, and 1235-1422 sites and 32-41 taxa for $16 \mathrm{~S}$ rDNA alignments. PAUP* (Swofford, 2003) was used to infer phylogenies by minimum evolution (ME) and maximum parsimony methods. Distances were calculated on the basis of the GTR $+\Gamma+$ I model, with parameters including substitution rates, base frequencies, $\Gamma$ distribution parameter and proportion of invariable sites estimated from a neighbor-joining tree. The ME and maximum parsimony trees were inferred using a heuristic search with 100 random taxon addition replicates and tree bisection and reconnection branch swapping. Bootstrap analyses were based on 1000 replicates with the same search options except with 10 replicates of random taxon addition.
Distribution patterns of putative novel endobiotic bacteria of P. sphagnophila

Novel bacterial sequences identified from 16S rDNA libraries were further examined by PCR using sequence-specific primers. Tests were performed on three geographic collections of $P$. sphagnophila from Duncan's Cove, Harrietsfield Bog and French Mountain Bog. For each field sample, $\sim 30$ P. sphagnophila cells were collected for DNA extraction (as above). DNA was dissolved in $8 \mu \mathrm{l}$ of sterile water, of which $2 \mu \mathrm{l}$ was added to each PCR tube. Negative controls were prepared from the water used to perform the final cell wash, and used to check for the possibility of bacterial contaminants that might have been carried over during the wash step. These PCR tests were performed using 'universal' bacterial primers as the outer pairs (16S-0008-5' plus $16 \mathrm{~S}-1511-3^{\prime}$ or $16 \mathrm{~S}-$ 0012-5' plus $16 \mathrm{~S}-1508-3^{\prime}$ ), followed by the second amplification using inner primers that are specific to each sequence type. The amplified fragments were cloned and sequenced as described above.

\section{Light microscopy and TEM}

P. sphagnophila was observed with a Zeiss Axiovert $200 \mathrm{M}$ (Jena, Germany) and photographs were taken with Hamamatsu ORCA-R2 (Hamamatsu, Japan) and Zeiss Axiocam HRC (Jena, Germany) digital cameras. Seven fixation protocols were tested for transmission electron microscopy (TEM), with the following procedure yielding the best results. Field samples containing P. sphagnophila were fixed in a mixture of glutaraldehyde (final concentration of $2 \%$ ) and osmium tetroxide (final concentration of $1 \%$ ) buffered with $0.05 \mathrm{M}$ cacodylate ( $\mathrm{pH} 7.4$ ) for $10 \mathrm{~min}$, followed by three 10-min washes in the buffer solution. Samples were fixed secondarily with $2 \%$ osmium tetroxide (final concentration) for $40 \mathrm{~min}$ and washed $10 \mathrm{~min}$ each for three times in a dilution series of the buffer with the last wash in sterile water. All the fixation and washing steps were performed on ice. As field samples contained a large amount of detritus and other organisms, 20200 P. sphagnophila cells were isolated using a micropipette, washed as described above and encased in $2 \%$ agarose gel. Each agarose piece was dehydrated in an ethanol series and embedded in Spurr's resin. Ultra-thin sections were stained with uranyl acetate in $50 \%$ ethanol and lead citrate, and examined using a Tecnai 12 transmission electron microscope (FEI, Hillsboro, OR, USA; Philips).

\section{Single-cell-level microspectrophotometry}

The absorption and fluorescence spectra of the pigmented endobiont of $P$. sphagnophila were measured using bright-field microscopes (BX51; Olympus, Tokyo, Japan; and Eclipse E600; Nikon, Tokyo, Japan) equipped with multichannel photodiode array detectors (PMA-11; Hamamatsu Photonics, Hamamatsu, Japan; MCPD-7000, Ohtsuka Electronics, Hirakata, Japan) (Murakami et al., 2004; Hirose et al., 2009). 


\section{DAPI staining and FISH}

For each paraffin embedding, about 3000 cells of $P$. sphagnophila were isolated using a micropipette, fixed in $10 \%$ acetate-buffered formalin for 1-5 days and encased in $2.5 \%$ agarose gel. The agarose plug was placed in a cassette and processed-ethanol dehydration, clearing and paraffin wax infiltration-using a Leica tissue processor (model ASP300 S; Wetzlar, Germany). The infiltrated agarose plug was placed in a cast, embedded in paraffin and solidified at $4{ }^{\circ} \mathrm{C}$ for $15 \mathrm{~min}$. Sections about $5 \mu \mathrm{m}$ thick were cut using a Reichert-Jung rotary microtome (Leica, Wetzlar, Germany), placed in warm water and collected on Superfrost Plus glass slides (Fisher Scientific, Waltham, MA, USA). Immediately before use, sections were de-waxed with three 5-min washes of xylene, re-hydrated in an ethanol series and washed in pure water. A section was covered with a drop of $4^{\prime}, 6$-diamidino-2-phenylindole (DAPI) solution $\left(1 \mu \mathrm{g} \mathrm{ml}^{-1}\right)$ for $5 \mathrm{~min}$ in the dark and washed with water for $5 \mathrm{~min}$ and $80 \%$ ethanol for 2 min before being mounted with AF1 (Citifluor Ltd, Leicester, UK).

For tyramide signal amplification (TSA)-FISH, de-waxed sections or whole cells that were formalin-fixed, collected onto polycarbonate filters $(0.8 \mu \mathrm{m}$; Sterlitech, Kent, WA, USA) and ethanoldehydrated, were treated with $0.02 \mathrm{M} \mathrm{HCl}$ for $20 \mathrm{~min}$ to inactivate endogenous peroxidase activity. Oligonucleotides conjugated with horseradish peroxidase were purchased from biomers.net (Germany). Probe specificity was tested by in silico analysis using probeCheck (Loy et al., 2008). A probe that targets an unrelated marine eukaryote (unpublished) was used as a negative control. Sections were covered with a hybridization mixture that contained $0.5 \mathrm{pmol}_{\mu \mathrm{l}}^{-1}$ horseradish peroxidase probe buffered in a hybridization solution ( $900 \mathrm{mM} \mathrm{NaCl,} 20 \mathrm{mM}$ Tris ( $\mathrm{pH} 7.5$ ), $0.01 \%$ sodium dodecyl sulfate, $40 \%$ de-ionized formamide, $2 \%$ blocking reagent; final concentrations) and incubated in a humidity chamber for $18 \mathrm{~h}$ at $35{ }^{\circ} \mathrm{C}$. Unbound probe was removed by two 20min washes at $37^{\circ} \mathrm{C}$ in a pre-warmed wash buffer (37 mM NaCl, $5 \mathrm{mM}$ EDTA, $20 \mathrm{mM}$ Tris (pH 7.5), $0.01 \%$ sodium dodecyl sulfate; final concentrations). A TSA Plus Fluorescence System (PerkinElmer, Waltham, MA, USA) was used for fluorescein tyramide amplification. Specimens were mounted with AF1 (Citifluor Ltd) and observed using a Zeiss Axiovert 200M (Germany).

\section{Results}

Pigmented endobiont of P. sphagnophila

$P$. sphagnophila was detected throughout the year in the field sites, although qualitative observations of field samples suggest that they were most abundant during the summer. While attempts to bring $P$. sphagnophila into culture have thus far not been successful, we noted that $P$. sphagnophila grew in

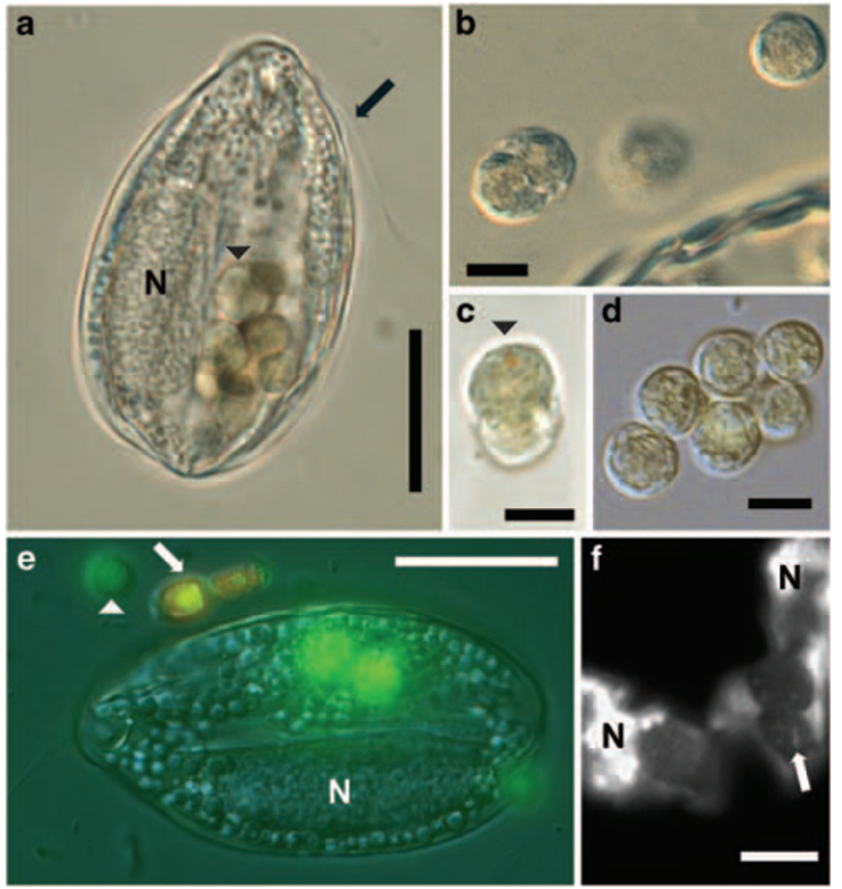

Figure 1 Light micrographs of $P$. sphagnophila cells and its pigmented endobiont.(a) Bright-field image of P. sphagnophila, showing a single emergent flagellum (arrow), a nucleus $(\mathrm{N})$ and several pigmented endobionts (arrowhead). (b, c) Pigmented endobionts released from $P$. sphagnophila cells broken open with a needle tip. Note that the cell on the left (in panel b) appears to be dividing, as well as the presence of a characteristic red spot (arrowhead in panel c). (d) A cluster of free-living cells that resemble the $P$. sphagnophila endobiont and were present in the same field samples. (e) Overlay of green (with No. 10 filter set) and red (with No. 15 filter set) fluorescence and DIC images. An Anabaena-like cyanobacterium (arrow) appears yellow due to comparatively stronger red emission than green emission, and is easily distinguished from the P. sphagnophila endobiont. A freeliving cell (arrowhead) has a similar morphology and fluorescence to the P. sphagnophila endobiont. Abundant and highly granular inclusions throughout the cytoplasm may be paramylon (carbohydrate) storage granules. (f) DAPI-stained paraffin thin section, showing the intensely stained nucleus (N) and lightly stained material inside the pigmented endobiont (arrow). Scale bars $=20 \mu \mathrm{m}$ (a, e); $5 \mu \mathrm{m}$ (b, c, d, f). DAPI, 4',6-diamidino-2phenylindole; DIC, differential interference contrast.

some field samples. For instance, the number of $P$. sphagnophila cells in a sample collected in December of 2008 had increased markedly when checked 7 months later. As is the case for $P$. sphagnophila of European peatlands (Schnepf et al., 2002), P. sphagnophila of North America also contains olive green-colored globular particles, with an average of $4-8$ per cell and each being $\sim 5 \mu \mathrm{m}$ in diameter (Figure 1a). When stored under low-light conditions, the globular particles appeared to darken in color, suggesting that their pigmentation might be regulated by light. In some field samples, similarly sized free-floating cells morphologically similar to the green-pigmented particles inside P. sphagnophila were observed (Figure 1d). Such cells also showed autofluorescence characteristics similar to those of the $P$. sphagnophila particles-both 
possess stronger green (with No. 10 filter set) and weaker red (with No. 15 filter set) fluorescence as compared with those of cyanobacteria (for example, Anabaena, Merismopedia) found in the same field samples (Figure 1e). Both intracellular green bodies and the free-floating cells also showed a faint red spot (which was difficult to capture with a digital camera) near the periphery (Figure 1c). Unlike the pigmented particles of $P$. sphagnophila, the free-floating cells were not bound by an extra vacuolar membrane. These observations suggest that the pigmented particles inside $P$. sphagnophila are taken up from the environment. Occasionally, $P$. sphagnophila cells were seen with a similarly sized pigmented particle attached to the base of its flagellum, although we are not certain whether such particles are actually being ingested by the protist. The pigmented particles of $P$. sphagnophila appear to divide by binary fission (Figures $1 \mathrm{~b}$ and $2 \mathrm{~h}$ ) and DAPI staining is consistent with the presence of DNA (Figure 1f). The green-pigmented particles persist inside $P$. sphagnophila cells for extended periods of time and are thus referred to here as pigmented endobionts.

When viewed by TEM, the pigmented endobionts appeared highly membranous in nature (Figure 2). Although its interior was found to be similar among the many individual particles we examined, the nature of the endobiont's periphery varied among different endobionts, even those within the same host (Figures 2c and e-h). The endobionts were located within host vacuoles, but some were surrounded by additional membranes (Figure 2e).
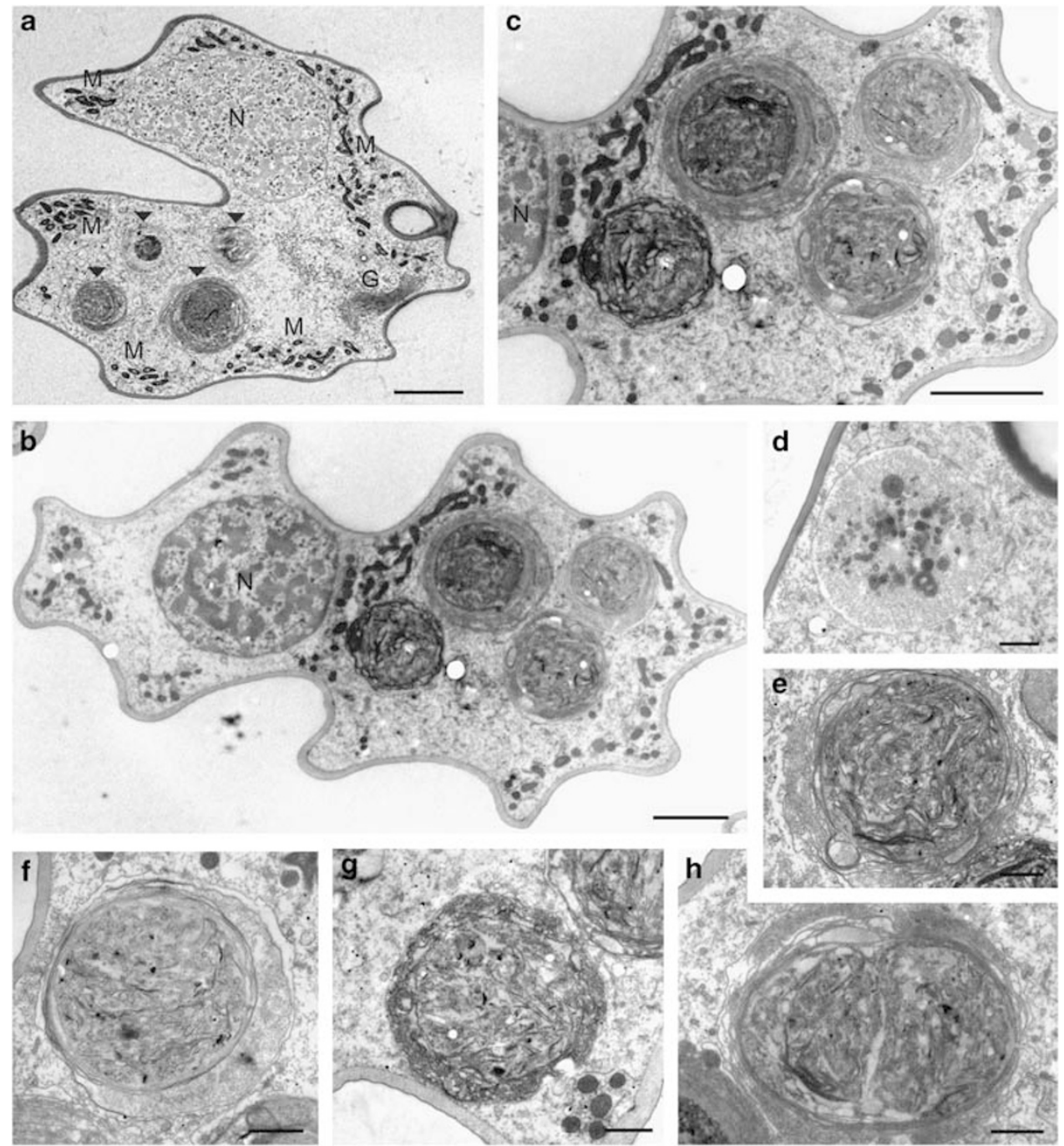

Figure 2 Transmission electron micrographs of $P$. sphagnophila.(a) An oblique section of the cell, showing the nucleus (N), Golgi apparatus (G), numerous mitochondria (M) and four pigmented endobionts (arrowheads). (b) A cross-section of P. sphagnophila, showing the nucleus $(\mathrm{N})$ and four pigmented endobionts. (c) Enlarged view of the pigmented endobionts. Note that each endobiont is enclosed by a host-derived vacuole. (d) Late-stage digestive vacuole. (e) A pigmented endobiont surrounded by multiple layers of membrane and with a highly membranous internal structure. (f) An example of the pigmented endobiont whose periphery is surrounded by several layers of membrane and by a lightly stained mucilaginous matrix. (g) A pigmented endobiont whose periphery consists of dense bundles of membranes. (h) Pigmented endobiont that appears to be dividing. Scale bars $=5 \mu \mathrm{m}$ (a); $3 \mu \mathrm{m}(\mathbf{b}, \mathbf{c}) ; 1 \mu \mathrm{m}(\mathbf{d}-\mathbf{h})$. 
Other endobionts were bound by a layer of lightly stained mucilage-like material (Figure 2f), which was also detected in some of their 'free-living' counterparts (data not shown). Still others had a periphery consisting of dense bundles of membranelike material that are collectively easily distinguished from the interior portion (Figure 2g). In addition, $P$. sphagnophila typically possessed one or more digestive vacuoles $\sim 4-5 \mu \mathrm{m}$ in size that contained disrupted cells or various debris (Figure 2d). The digestive vacuoles were surrounded by several secondary vacuoles that are, on average, less than $200 \mathrm{~nm}$ in diameter (not shown), suggesting that they are at a late stage of digestion (Jurand, 1961).

On the basis of light and scanning electron microscopy, Schnepf et al. (2002) proposed that the pigmented endobionts of $P$. sphagnophila are Synechocystis-like cyanobacteria with phycocyanin. However, the pigmented endobionts analyzed here lack the typical absorption or fluorescence emission bands of phycobilins (phycocyanin or phycoerythrin) (Figure 3) (for example, references Wolf and Schussler, 2005; Six et al., 2007). By contrast, the cyanobacterium Synechocystis sp. PCC6803 has an absorption band around $625 \mathrm{~nm}$ and fluorescence bands around $640 \mathrm{~nm}$, which correspond to C-phycocyanin (Figure 3). Interestingly, the pigmented endobiont shows a small absorption band around $670 \mathrm{~nm}$ and multiple overlapping fluorescence bands between $670 \mathrm{~nm}$ and $690 \mathrm{~nm}$, which might indicate the presence of chlorophyll-a (Figure 3). However, chlorophyll- $a$-containing organisms usually show a single sharp fluorescence band around $685 \mathrm{~nm}$ at room temperature (for example, Murakami et al., 2004). Another oddity of the $P$. sphagnophila endobiont is the presence of an absorption band at $845 \mathrm{~nm}$ and fluorescence bands

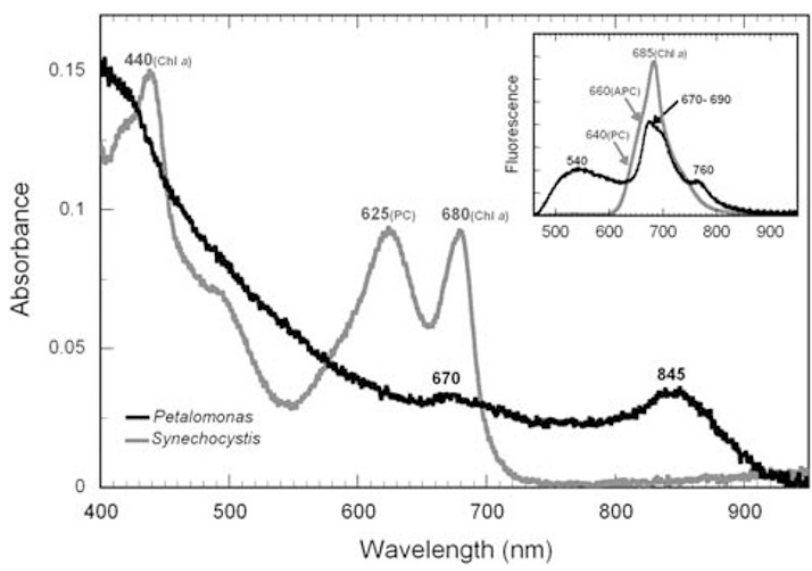

Figure 3 The absorption and fluorescence (inset) spectra of the pigmented endobiont of $P$. sphagnophila (black lines) and the cyanobacterium Synechocystis sp. PCC6803 (gray lines). Fluorescence spectra were measured with excitation at $435 \mathrm{~nm}$. The absorbance and fluorescence intensities are arbitrarily scaled for simple comparison. Abbreviations: Chl $a$, chlorophyll-a; PC, phycocyanin; APC, allophycocyanin. at $540 \mathrm{~nm}$ and $760 \mathrm{~nm}$; the former absorption band cannot be from bacteriochlorophyll- $a$ as a corresponding fluorescence band is missing (Figure 3).

Wide diversity of bacterial endobionts in P. sphagnophila In addition to the large pigmented endobionts described above, several different types of small bacterial or bacteria-like cells were observed in the cytoplasm of $P$. sphagnophila by TEM (Figures 4 and 5). The abundance and morphological diversity of these bacteria varied among different geographic collections and even within the same geographic collections sampled at different time points (data not shown). A rod-shaped Gram-negative bacterium, $0.5 \mu \mathrm{m}$ in length and $0.15 \mu \mathrm{m}$ in diameter, was common in the Harrietsfield Bog collection (Figures $4 \mathrm{a}$ and $\mathrm{b}$ ). This bacterium was surrounded by three membranes, with the outermost layer presumably derived from the host endomembrane system (Figure 4a). On the basis of morphology and 16S rDNA library sequence data (see below), this bacterium is most likely a novel Rickettisales bacterium (R1 type) (Supplementary Table S2). A somewhat bigger bacterium, $1 \mu \mathrm{m}$ in length and $0.3 \mu \mathrm{m}$ in diameter, was found in the Lizard Lake collection (Figures 4c and d). This bacterium resided freely within the host cytoplasm. There were also other inclusions seen near mitochondria and the nucleus, which might be of bacterial origin (Figures $5 \mathrm{~b}$ and c), but our transmission electron micrographs did not show typical bacterial cell wall structures so we cannot be certain-they might instead be some form of microbody (that is, a cytoplasmic organelle, such as a peroxisome, that is usually ovoid in shape and bound by a single membrane).

\section{Molecular sequencing and phylogenies}

The 18S rDNA sequences amplified from three geographic collections of $P$. sphagnophila were $\sim 98 \%$ identical to each other and were closely related to that of Petalomonas cantuscygni (with sequence identities of $\sim 84 \%$ ), a marine Petalomonas species that is much smaller than $P$. sphagnophila (Figure 6). Notosolenus ostium, a Petalomonas-like heterotrophic euglenid, is sister to the Petalomonas species in our 18S rDNA tree (Figure 6). Within the Euglenozoa, Petalomonas branches with other euglenids, although the bootstrap support for this position is weak.

We tried to determine the identity of the pigmented endobiont by PCR using several cyanobacteriumspecific and 'universal' bacterial 16S rDNA primers (Supplementary Table S1). However, no cyanobacterial sequences were amplified from $P$. sphagnophila cells under a wide range of PCR conditions, which is in agreement with the unusual spectral patterns of the pigmented endobiont, suggesting that it may not be a cyanobacterium. Although 

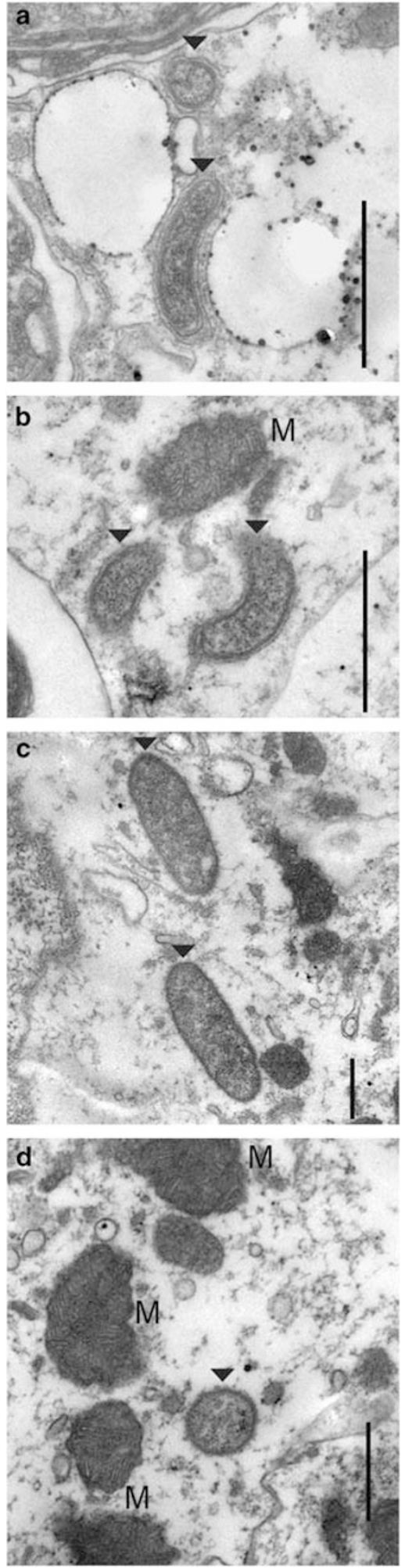

Figure 4 Transmission electron micrographs of bacteria occurring inside $P$. sphagnophila. $(\mathbf{a}, \mathbf{b})$ Vibrio-shaped bacterium (arrowhead) detected in the Harrietsfield Bog collection. Note that the bacterium is located within a host-derived vacuole. (c, d) Longitudinal (c) and cross-sectional (d) views of bacteria found in the Lizard Lake collection. Scale bars $=0.5 \mu \mathrm{m}(\mathbf{a}-\mathbf{d})$.
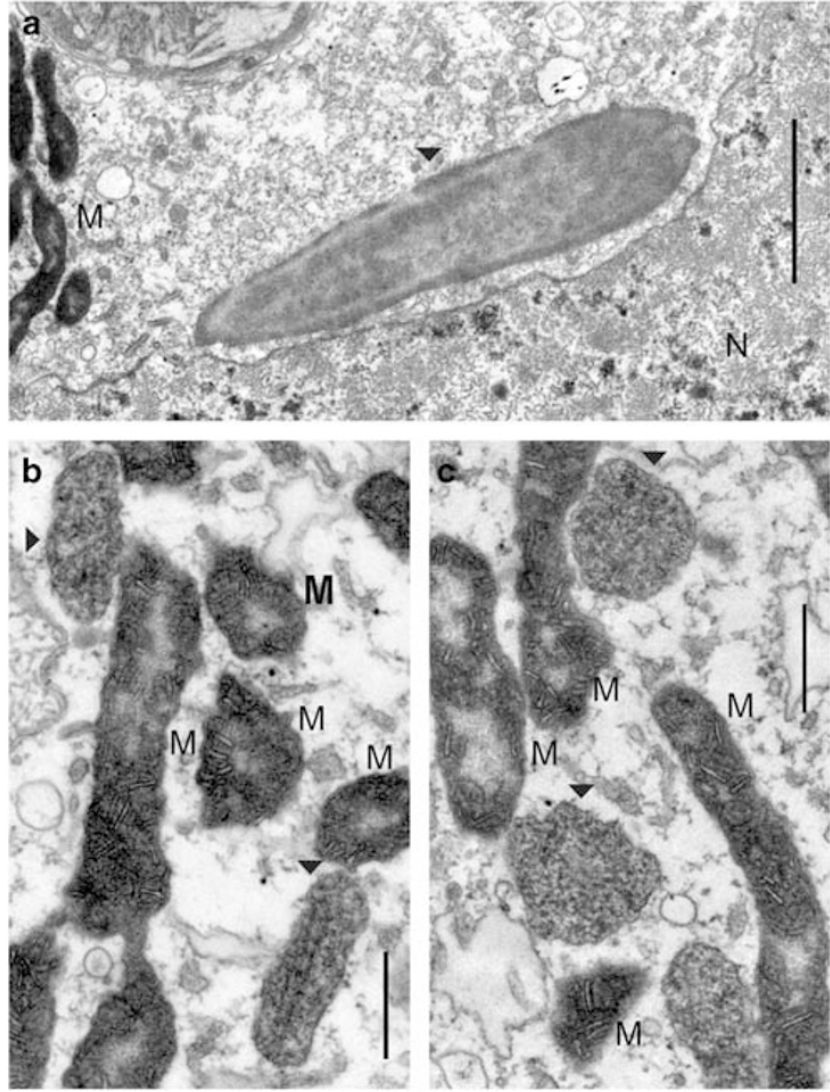

Figure 5 Transmission electron micrographs of possible bacteria detected in the $P$. sphagnophila cytoplasm.(a) A single large elongated rod-shaped particle (arrowhead) situated adjacent to the nucleus $(\mathrm{N})$, detected from at least two separate geographic collections. (b) Rod-shaped particles, near mitochondria (M), with characteristic longitudinal filaments, detected from the Duncan's Cove collection. (c) Globular particles (arrowheads) located among mitochondria (M), from the Duncan's Cove collection. Scale bars $=2 \mu \mathrm{m}$ (a), $0.5 \mu \mathrm{m}(\mathbf{b}, \mathbf{c})$.

cyanobacterial sequences were not detected, a number of other bacterial sequences were present in $16 \mathrm{~S}$ rDNA libraries that were generated using 'universal' bacterial $16 S$ rDNA PCR primers. In total, we obtained and analyzed $\sim 230$ sequences from 14 clone libraries derived from four geographic collections of $P$. sphagnophila (Supplementary Table S2). Several sequences showed $99-100 \%$ identity to known bacterial sequences, but most of these, except for those of Staphylococcus and Pseudomonas, were detected in only one sequence library (Supplementary Table S2). Here, we focused on novel bacterial sequence types that showed maximum sequence identities no greater than $90 \%$ to GenBank database entries and that were detected from more than one geographic collection (Supplementary Figure S2 and Table 1). In total, five novel sequence types were identified: a firmicute, two rickettsias, and $\delta$ and $\gamma$ proteobacterial types (Figure 7). Our PCR tests strongly suggest that these sequences were amplified from $P$. sphagnophila cells and not from bacterial contaminants in the 
surrounding liquid medium, because they were not amplifiable from DNA purified from the last cell wash solution (data not shown). In addition, none of these five bacterial sequences were amplifiable from a drop of Duncan's Cove water sample, about $100 \mu \mathrm{l}$ in volume, from which $P$. sphagnophila cells were removed. These results, together with TSA-FISH data (below), suggest that the five novel bacteria may almost exclusively occur inside $P$. sphagnophila in natural environments.

Phylogenetic analyses suggest that three of the five novel bacteria, two rickettsias (R1, R2 types) and one gamma proteobacterium (G-type), are related to strictly intracellular bacteria such as Rickettsia and Coxiella (Figures 7b and c). One bacterium is most closely related to the delta proteobacterium Spirobacillus cienkowskii (Figure 7d),

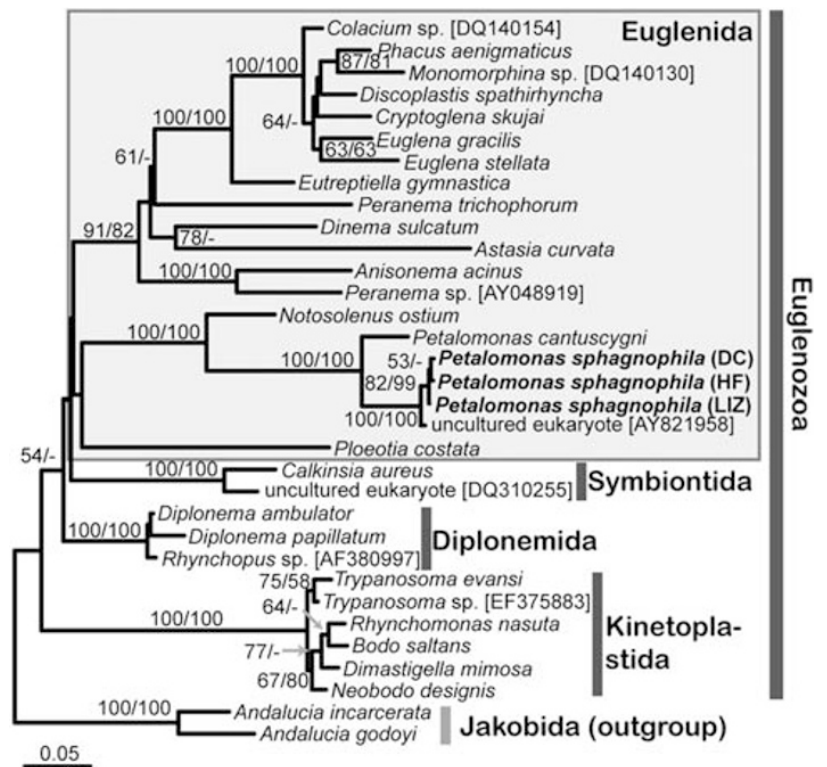

Figure 6 Phylogenetic analysis of $P$. sphagnophila $18 \mathrm{~S}$ rDNA sequences. The tree shown is an ME distance tree (GTR $+\Gamma+\mathrm{I}, 4$ rate categories) showing the position of $P$. sphagnophila within the Euglenida. Newly obtained sequences are in bold text. The tree is arbitrarily rooted using representative sequences from the Jakobida. ME distance and maximum parsimony bootstrap values over $50 \%$ are shown at the corresponding nodes. The scale bar indicates the inferred number of nucleotide substitutions per site. Abbreviations: DC, Duncan's Cove; HF, Harrietsfield Bog; LIZ, Lizard Lake; ME, minimum evolution; rDNA, ribosomal DNA. which is a pathogen of freshwater Daphnia species (Rodrigues et al., 2008). Lastly, one bacterium belongs to the phylum Firmicutes, specifically to Thermoactinomycetaceae (Figure 7a).

To determine whether these sequences belong to bacteria that are located in the $P$. sphagnophila cytoplasm, four of them were examined using TSAFISH. The results show that they are indeed intracellular bacteria of $P$. sphagnophila (Figure 8). Two rickettsias, corresponding to the R1 and R2 sequence types, were less than $1 \mu \mathrm{m}$ in width and occurred in the cytoplasm (Figures $8 \mathrm{~b}, \mathrm{~d}$ and e). The delta proteobacterium (D-type), conversely, appeared to be slightly bigger than the two rickettsias and was generally localized to the anterior end of the protist (Figure 8c). The firmicute endobiont was thickly rod-shaped and over $5 \mu \mathrm{m}$ in length, occurring in the center of the protist (Figure 8a). It has a morphology similar to a large rod-shaped particle, about $8 \mu \mathrm{m}$ in length and $1.4 \mu \mathrm{m}$ or more in width, observed by TEM (Figure 5a).

To better understand how these five endobionts associate with the $P$. sphagnophila host in natural environments, $\sim 30$ cells of $P$. sphagnophila were isolated from fresh (less than a week old) field samples and processed for DNA purification and PCR testing using specific primer sets. Consistent with TEM data, the types of bacterial sequences detected in different $P$. sphagnophila collections were highly variable, depending on the geographic locations and on the sampling times (for example, Table 1). For instance, of the sequence types examined, the R1-type rickettsia is the dominant endobiont of P. sphagnophila in Harrietsfield Bog (Table 1 and Supplementary Table S2), whereas the gamma proteobacterium (G-type) detected from one Lizard Lake collection appeared absent in other Lizard Lake collections sampled at different time points (data not shown).

\section{Discussion}

General features and molecular phylogeny of P. sphagnophila

Our study provides the first description of $P$. sphagnophila from North America, which previously has been reported only from Europe (Schnepf et al.,

Table 1 Distribution of the five putative endobiotic bacteria among three geographic collections of P. sphagnophila

\begin{tabular}{llll}
\hline Sequence origins (below) & Duncan's Cove & Harrietsfield Bog & French Mountain Bog \\
\hline Rickettsiales (R1) & Present & Present & Present \\
Rickettsiales (R2) & Present & Not detected & Present \\
$\delta$ proteobacterium (D) & Not detected & Not detected & Present \\
$\gamma$ proteobacterium (G) & Present & Not detected & Not detected \\
Firmicute (F) & Present & Not detected & Present
\end{tabular}

Presence or predicted absence of each bacterial type is based on PCR amplification using each sequence-specific primer set followed by sequencing verification. 


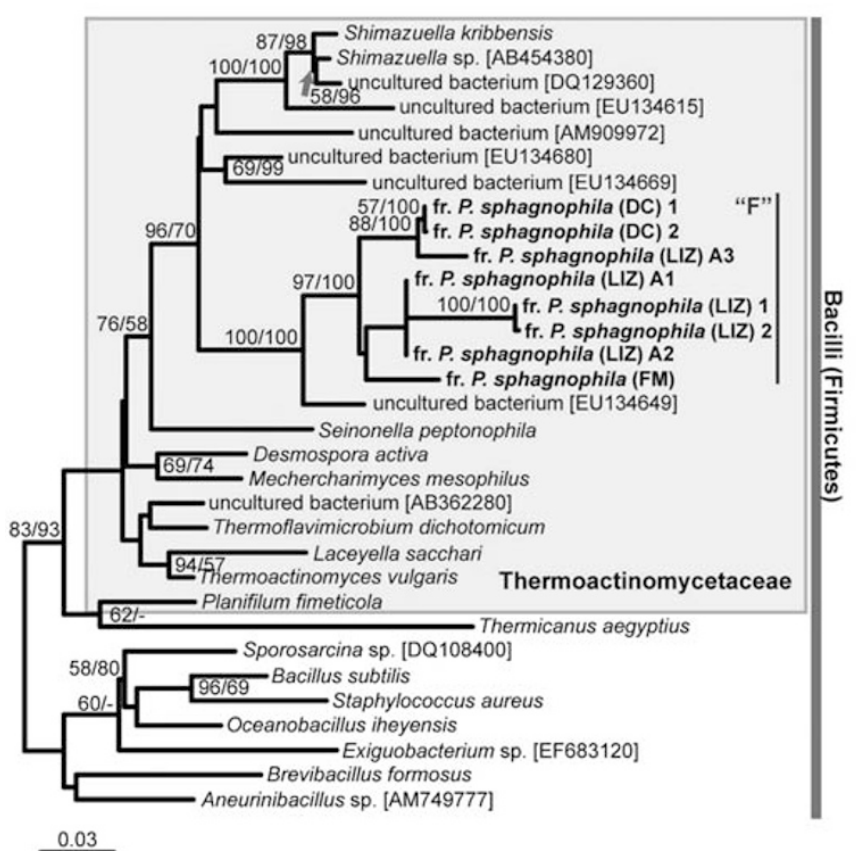

$\underline{0.03}$

c

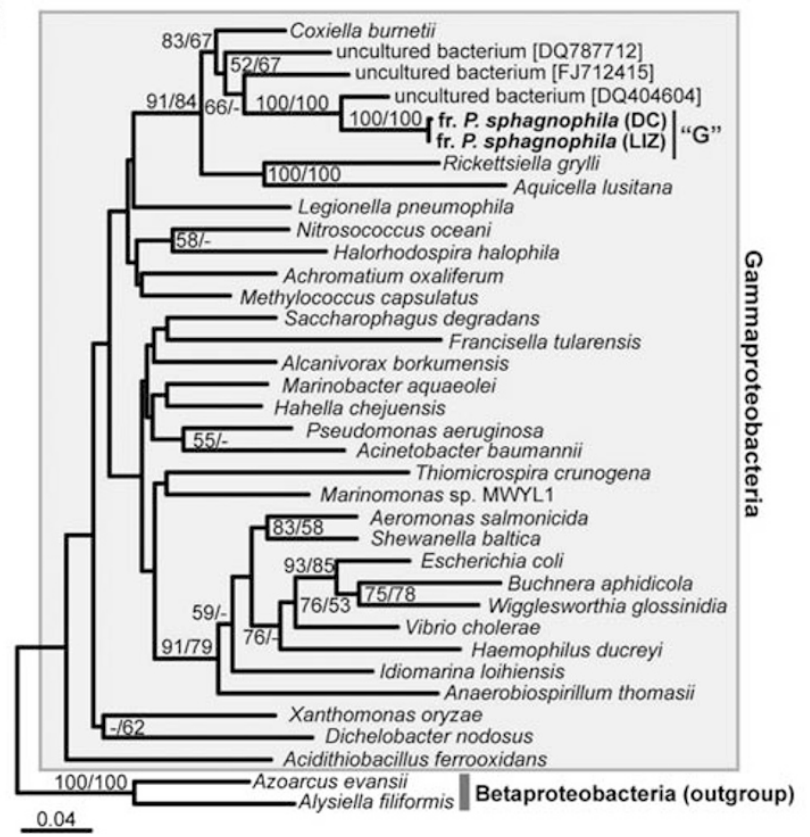

b

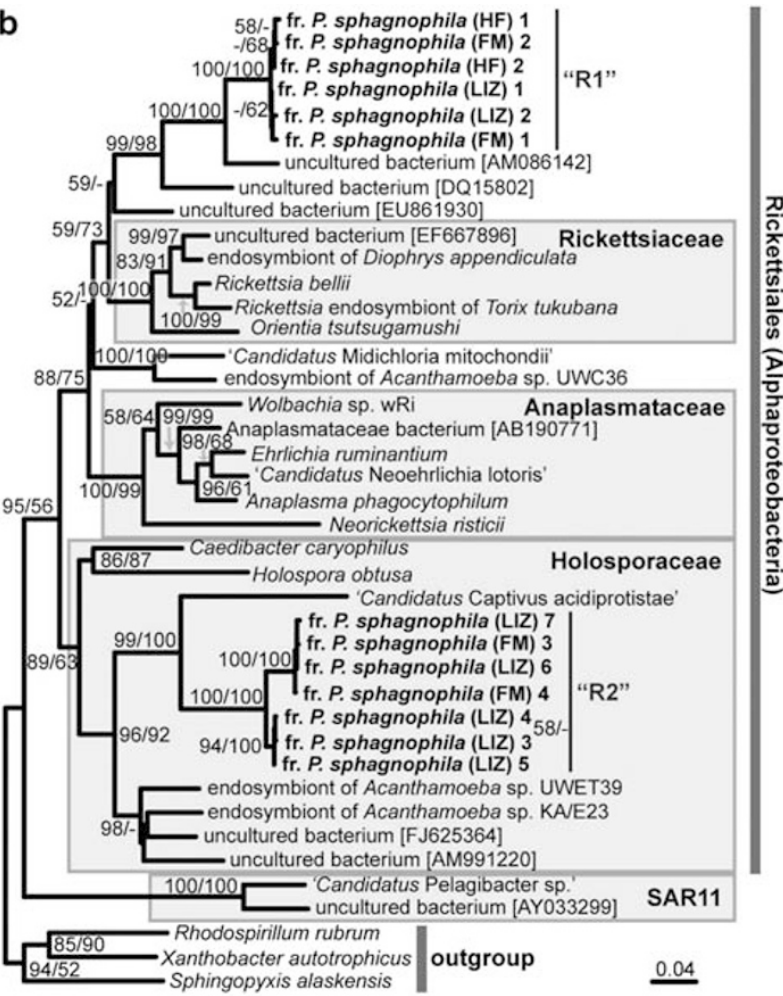

d

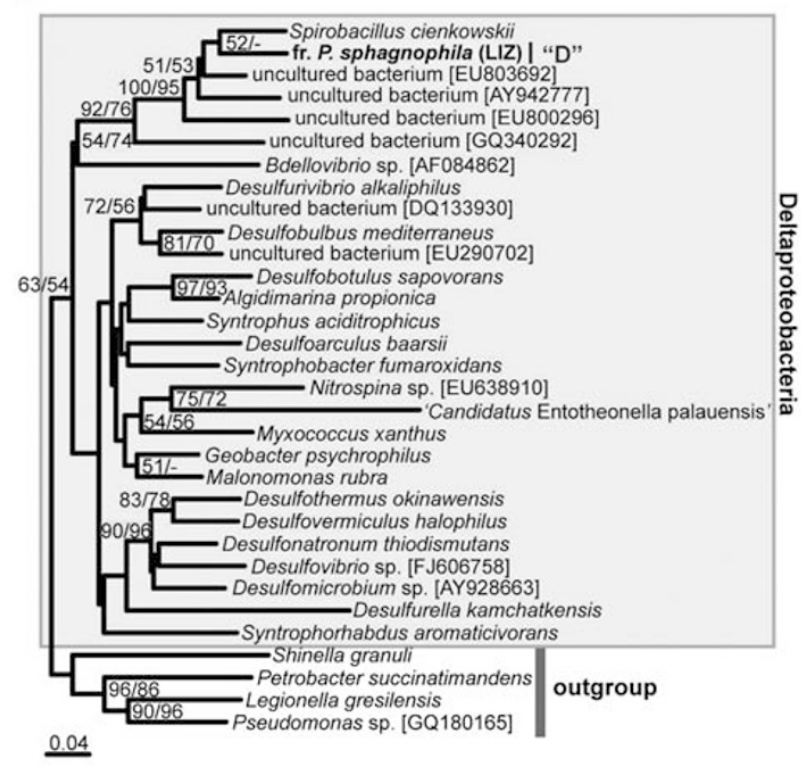

Figure 7 16S rDNA phylogenies of five novel bacterial sequence types that were amplified from P. sphagnophila. ME distance (GTR $+\Gamma+\mathrm{I}$, four rate categories) trees are shown. ME distance and maximum parsimony bootstrap values over $50 \%$ are shown at the corresponding nodes.(a) Novel firmicute bacterial sequences, F, obtained from three geographic collections of P. sphagnophila. (b) Two different types of Rickettsiales sequences: R1 and R2. (c) Novel gamma proteobacterial sequences, G, obtained from the Lizard Lake and Duncan's Cove (DC) collections. (d) Novel delta proteobacterial sequence from the Lizard Lake collection. New sequences obtained in this study are indicated in bold text. The scale bars indicate the estimated number of nucleotide substitutions per site. Abbreviations: DC, Duncan's Cove; FM, French Mountain Bog; HF, Harrietsfield Bog; LIZ, Lizard Lake; ME, minimum evolution; rDNA, ribosomal DNA.

2002). Found in all four peatland sites investigated from Nova Scotia, Canada, P. sphagnophila appears to be ubiquitous in these peatland ecosystems. In some samples surveyed, $P$. sphagnophila represented the largest fraction of the total microbial eukaryotic biomass (data not shown), suggesting that it may contribute greatly to peat decomposition processes. 

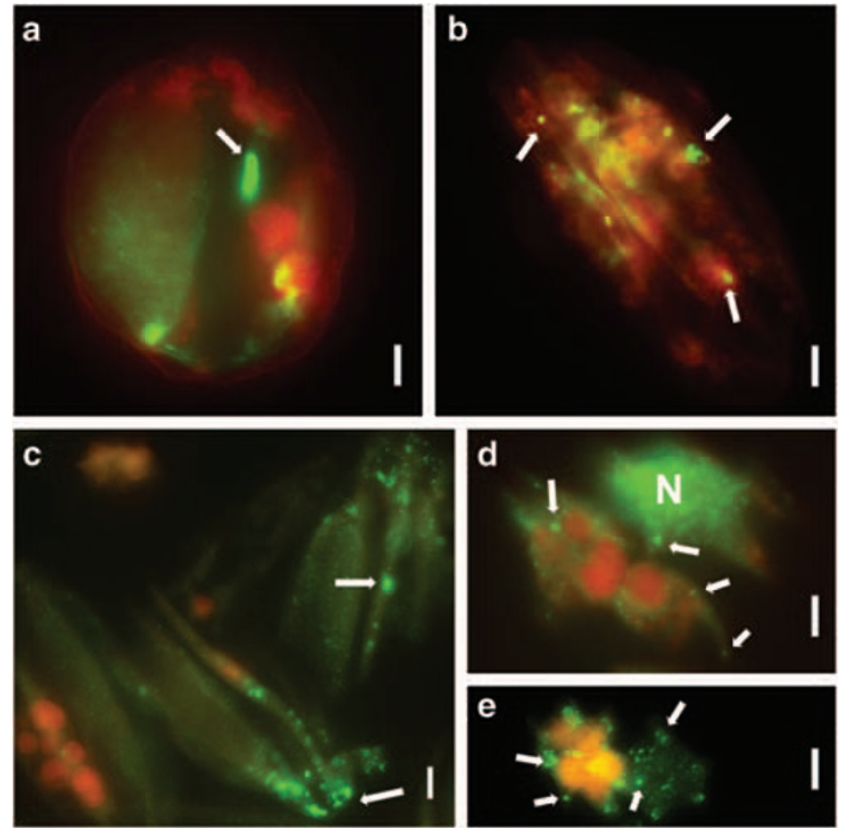

Figure 8 TSA-FISH images showing putative endobionts (in green) of $P$. sphagnophila. In situ hybridizations were performed using whole cells (a, b) or paraffin-embedded sections (c-e). Overlay of GFP and red channels (No. 15 filter set) are shown to visualize the fluorescein-labeled bacteria and the autofluorescent endobionts, respectively.(a) A novel putative firmicute bacterium appears as a large elongated rod-shaped cell and occurs singly in the cytoplasm (arrow), detected from the Lizard Lake collection. (b) View from one side of P. sphagnophila, showing several pigmented endobionts and Rickettsiales bacterial cells (R2-type, arrow), observed from the French Mountain Bog collection. (c) A novel delta proteobacterium detected near the anterior end of the host protist from the Lizard Lake. (d, e) Rickettsiales bacterium (R1-type) detected in the Harrietsfield Bog collection. Nonspecific hybridization, especially to the nucleus, was occasionally observed (as in panel d; also see Supplementary Figure S2). However, such non-specific signal appeared as evenly distributed and relatively weak hybridization spots $(<0.2 \mu \mathrm{m})$, in contrast to more sparsely distributed genuine signals. Scale bars $=5 \mu \mathrm{m}$ (a-e). FISH, fluorescence in situ hybridization; TSA, tyramide signal amplification.

From an evolutionary perspective, the genus Petalomonas, which includes about 60 described species, is regarded as an 'early-diverging' euglenid lineage based on analysis of morphology as well as preliminary molecular sequence data (Leedale and Vickerman, 2000; Busse et al., 2003; Breglia et al., 2007). For instance, Petalomonas is ancestrally plastid-lacking, has a small number of pellicular strips, is rigid and is characterized as feeding on bacteria using a relatively simple feeding system known as a Type-1 apparatus, all of which have been argued to be ancestral states for euglenids (Leander et al., 2007). Among Petalomonas, only one species, $P$. cantuscygni, has been brought into culture and, therefore, the biology of the substantial diversity of species within this genus is poorly understood. For example, the contentions that Petalomonas is primarily bacterivorous (rather than eukaryvorous) and has a simple feeding apparatus are based heavily on observations of $P$. cantuscygni and might not be broadly representative of the genus as a whole. Consistent with morphology-based classification, our 18S rDNA phylogenies including newly obtained sequences from $P$. sphagnophila show that it is closely related to marine P. cantuscygni (Figure 6).

One of the most distinctive features of $P$. sphagnophila is the presence of several autofluorescent, pale green-pigmented, cytoplasmic particles per cell (Schnepf et al., 2002). P. sphagnophila almost always had such particles, although a few cells, out of tens of thousands of cells observed during the course of our study, appeared colorless. Given that numerous similarly sized, but non-fluorescent, particles exist in the field samples, $P$. sphagnophila appears to be highly selective in the uptake (or at least retention) of the pigmented particles. As the pigmented particles persist inside $P$. sphagnophila for several weeks or more (Schnepf et al., 2002), the host protist might benefit by keeping them alive, or even allowing them to grow for extended periods of time instead of digesting them immediately.

\section{The pigmented endobiont may not be a cyanobacterium}

On the basis of preliminary autofluorescence observation, Schnepf et al. (2002) proposed that the pigmented particles of $P$. sphagnophila were endobiotic cyanobacteria. Having discovered P. sphagnophila in the peatlands of Nova Scotia, the initial goal of our study was to confirm or refute this hypothesis by obtaining molecular sequence data from these particles. However, no cyanobacterial sequences were amplifiable from $P$. sphagnophila DNA in our study, despite the use of different PCR primer pairs designed to target most of the known diversity of cyanobacteria (Supplementary Table S1). Furthermore, comprehensive analyses of $16 \mathrm{~S}$ rDNA clone libraries generated using 'universal' bacterial primers also did not produce any sequences of cyanobacterial origin (Supplementary Table S2). Finally, the pigmented endobiont has unusual absorption and fluorescence emission spectra (Figure 3), which distinguish it from typical cyanobacteria (or eukaryotic algae) that we know of. We presently do not know the chemical basis of the green, autofluorescent pigment contained in the endobiont. Therefore, whether or not the endobiont is actually photosynthetic remains unknown.

One of the interesting characteristics of the P. sphagnophila endobiont is the presence of a red spot on or near its surface (Figure 1c). Significantly, free-floating cells with similar morphology and autofluorescence to the endoboint also had a red spot, consistent with the notion that the P. sphagnophila endobiont is acquired from the environment. The probable presence of DNA (as seen by DAPI staining; Figure 1f) and the observation of apparently dividing cells further strengthen the 
connection between the pigmented particle and free-living cells, which are most likely prokaryotic in nature as they lack obvious organelle-like structures. However, the endobiont was not labeled with any of the probes that we designed to target four of five novel bacterial 16S rRNA sequence types; these probes instead localized to different cellular inclusions of P. sphagnophila (Figure 8). It is interesting to note that apparent close relatives of the organism from which our novel gamma bacterium sequence (G) derives, such as Coxiella and Rickettsiella species (Figure 7c), do not have membranous structures or autofluorescent materials and are smaller (usually $<1 \mu \mathrm{m}$ in length; Brenner et al., 2005) than the pigmented endobiont of $P$. sphagnophila. Other 16S rDNA sequences isolated from our clone libraries were even more similar to those of known bacteria ( $>99 \%$ identical; Supplementary Table S2), and to our knowledge none of these bacteria share morphological similarities with the pigmented endobiont either (for example, reference Brenner et al., 2005). Collectively, these observations suggest, but do not definitively prove, that despite the use of a battery of 'standard' archaeal and bacterial primers, none of bacterial sequence types we amplified by PCR are in fact derived from the pigmented endobiont. One explanation is that this endobiotic organism may have a highly derived 16S rDNA sequence. Consistent with this possibility is the fact that the standard bacterial probe EUB 338 (Amann et al., 1990) did not label the pigmented endobiont in TSA-FISH (data not shown). Alternatively, it is possible that our nucleic acid extraction procedures were unable to release DNA in sufficient quantity and/or quality to serve as template for PCR.

Phylogenetically diverse endobiotic bacteria inhabit the P. sphagnophila cytoplasm

While surveying $P$. sphagnophila by means of TEM and molecular sequencing, we detected several other types of possible prokaryotic endobionts, either enclosed in host-derived vacuoles or free in the cytoplasm (Figures 4 and 5). Molecular sequencing and TSA-FISH identified five novel bacterial endobionts associated with $P$. sphagnophila (Figures 7 and 8).

Of these five novel endobionts, three are related to strictly intracellular bacterial groups, the Rickettsiales ( $\alpha$-proteobacteria) and the genus Coxiella $(\gamma$-proteobacteria), in the $16 \mathrm{~S}$ rDNA phylogenies (Figures 7b and c). Rickettsias are found in many arthropod species as well as in vertebrate hosts, including humans, forming parasitic or mutualistic associations (Brenner et al., 2005). For instance, many Wolbachia endobionts are reproductive parasites in arthropod hosts, whereas those associated with filarial nematodes and the wasp Asobara tabida are mutualists (Fenn et al., 2006; Werren et al., 2008). Rickettsias have also been found in two protist groups, ciliates and the amoebozoan
Acanthamoeba, as well as in an acidophilic protist of unknown phylogenetic affinity (Baker et al., 2003; Pannebakker et al., 2007; Schmitz-Esser et al., 2008; Ferrantini et al., 2009). Coxiella and closely related Rickettsiella species were once assigned to the Rickettsiales ( $\alpha$-proteobacteria); they are, however, now known to have evolved an intracellular lifestyle independently within the $\gamma$-proteobacteria (Leclerque, 2008). The genus Coxiella is found in arthropods and vertebrate hosts, and includes $C$. burnetii, the causative agent of $\mathrm{Q}$ fever in humans (Brenner et al., 2005).

By contrast, the two other $P$. sphagnophila endobionts we identified are not close relatives of known intracellular bacteria. The novel delta proteobacterial endobiont is most closely related to Spirobacillus cienkowskii, which infects the planktonic crustacean Daphnia and propagates within the hemolymph (circulating fluid), thereby killing the infected hosts within 1-4 days (Rodrigues et al., 2008). However, unlike the P. sphagnophila endobiont, $S$. cienkowskii is not intracellular. Finally, the novel firmicute endobiont, detected in P. sphagnophila from all four peatland sites, belongs to the Thermoactinomycetaceae, a subclade of the Firmicutes (Figure 7a). The Thermoactinomycetaceae comprises eight genera and includes many thermophilic species such as Thermoactinomyces spp. as well as some that are mesophilic (Yoon et al., 2005; Yassin et al., 2009). None of the described species of the Thermoactinomycetaceae, however, are known to associate with eukaryotes (for example, references Yoon et al., 2005; Park et al., 2007), although we note that previous studies have focused on labcultured strains. Although the Thermoactinomycetaceae is characterized by branched mycelia with spores produced alongside them, the novel firmicute endobiont of $P$. sphagnophila appears to exist in a large elongate form (Figure 8a). In addition, the $16 \mathrm{~S}$ rDNA sequences of the novel firmicute are relatively long-branched as compared with those of free-living relatives (Figure 7a) and many of the sequences of this type were characterized by several internal deletions or inversions of $\sim 200 \mathrm{nt}$ (for example, GenBank accession numbers GU477299GU477305 and GU477321). These results suggest that the firmicute endobiont might be under an accelerated rate of evolution, as has been shown to be the case for obligate intracellular bacteria, whose genomes are characterized by massive sequence deletions and gene rearrangements (Wernegreen, 2005).

Analysis by TEM, library sequencing and PCR experiments on the basis of several geographic and temporal collections of $P$. sphagnophila suggest that these five novel bacteria collectively make up the predominant types of endobionts in this protist (excluding the pigmented endobiont whose origin remains unknown) but that their associations and disassociations with their host occur in a relatively short period of time. Over $85 \%$ of the $\sim 1.5$-kbp $16 \mathrm{~S}$ 
rDNA fragment library sequences, 114 out of 133 in total, correspond to the five endobiotic bacterial types (Supplementary Table S2). By contrast, these five sequence types represent only $23 \%, 20$ out of 87 , of the $\sim 600-b p$ or $\sim 1$-kbp fragment library sequences. One possible explanation for this difference is that successful amplification of DNA from rapidly degrading bacteria in food vacuoles would become progressively more difficult as the amplicon size increases; sequences from such organisms would thus be less represented in the 'large amplicon' libraries. Regardless, the patchy distribution of the five endobiotic bacterial types focused on here, comprehensively shown by our cultureindependent methods, supports an emerging view that protists are open systems in which new associations between eukaryotes and prokaryotes are continuously formed (Ferrantini et al., 2009). To further understand the functions of the P. sphagnophila endobionts and, in particular, to characterize the origin of its enigmatic pigmented endobiont, additional experiments are underway, including use of flow cytometry and whole-genome amplification procedures.

\section{Acknowledgements}

This study was supported by postdoctoral fellowships to EK and JSP from the Centre for Comparative Genomics and Evolutionary Bioinformatics at Dalhousie University and the Tula foundation; an operating grant (ROP85016) awarded to JMA from the Canadian Institutes of Health Research (CIHR) regional Partnership Program, together with the Nova Scotia Health Research Foundation (NSHRF); NSERC Grant 298366-04 awarded to AGBS; Research Program of Hayama Center for Advanced Studies of Sokendai to SM; and Grant-in-Aid for Creative Scientific Research 17GS0134 from the Japan Society for the Promotion of Science to AM. We thank D Spencer and J Hopkins for help with sample collection, S Whitefield for assistance with light microscopy and P Colp for help with paraffin embedding and sectioning. $B$ Leander is also thanked for assistance with interpretation of electron micrographs. JMA and AGBS are Fellows of the Canadian Institute for Advanced Research, Program in Integrated Microbial Biodiversity, and JMA is a Canadian Institutes of Health Research New Investigator.

\section{References}

Amann RI, Binder BJ, Olson RJ, Chisholm SW, Devereux R, Stahl DA. (1990). Combination of 16s rRNA-targeted oligonucleotide probes with flow cytometry for analyzing mixed microbial populations. Appl Environ Microbiol 56: 1919-1925.

Baker BJ, Hugenholtz P, Dawson SC, Banfield JF. (2003). Extremely acidophilic protists from acid mine drainage host Rickettsiales-lineage endosymbionts that have intervening sequences in their 16S rRNA genes. Appl Environ Microbiol 69: 5512-5518.
Breglia SA, Slamovits CH, Leander BS. (2007). Phylogeny of phagotrophic euglenids (Euglenozoa) as inferred from hsp90 gene sequences. J Eukaryot Microbiol 54: 86-92.

Brenner DJ, Krieg NR, Staley JT (eds) (2005). Bergey's Manual of Systematic Bacteriology, Volume Two: the Proteobacteria. Springer: New York.

Busse I, Patterson DJ, Preisfeld A. (2003). Phylogeny of phagotrophic euglenids (Euglenozoa): a molecular approach based on culture material and environmental samples. J Phycol 39: 828-836.

Dubilier N, Bergin C, Lott C. (2008). Symbiotic diversity in marine animals: the art of harnessing chemosynthesis. Nat Rev Microbiol 6: 725-740.

Fenchel T, Finlay BJ. (1991). Synchronous division of an endosymbiotic methanogenic bacterium in the anaerobic ciliate Plagiopyla frontata Kahl. J Protozool 38: $22-28$.

Fenn K, Conlon C, Jones M, Quail MA, Holroyd NE, Parkhill J et al. (2006). Phylogenetic relationships of the Wolbachia of nematodes and arthropods. PLoS Pathol 2: 887-899.

Ferrantini F, Fokin SI, Modeo L, Andreoli I, Dini F, Gortz HD et al. (2009). 'Candidatus Cryptoprodotis polytropus, a novel Rickettsia-like organism in the ciliated protist Pseudomicrothorax dubius (Ciliophora, Nassophorea). J Eukaryot Microbiol 56: 119-129.

Fokin SI, Schweikert M, Gortz HD, Fujishima M. (2003). Bacterial endocytobionts of Ciliophora. Diversity and some interactions with the host. Eur J Protistol 39: $475-480$.

Fokin SI. (2004). Bacterial endocytobionts of ciliophora and their interactions with the host cell. Int Rev Cytol 236: 181-249.

Gorham E. (1991). Northern peatlands: role in the carbon cycle and probable responses to climatic warming. Ecol Appl 1: 182-195.

Hirose E, Uchida H, Murakami A. (2009). Ultrastructural and microspectrophotometric characterization of multiple species of cyanobacterial photosymbionts coexisting in the colonial ascidian Trididemnum clinides (Tunicata, Ascidiacea, Didemnidae). Eur J Phycol 44: 365-375.

Horn M, Wagner M. (2004). Bacterial endosymbionts of free-living amoebae. J Eukaryot Microbiol 51: 509-514.

Jurand A. (1961). An electron microscope study of food vacuoles in Paramecium aurelia. J Protozool 8: 125-130.

Kim E, Archibald JM. (2009). Diversity and evolution of plastids and their genomes. In: Sandelius AS, Aronsson $\mathrm{H}$ (eds). The Chloroplast: Interactions with the Environment. Springer-Verlag: Berlin, pp 1-39.

Leander BS, Esson HJ, Breglia SA. (2007). Macroevolution of complex cytoskeletal systems in euglenids. Bioessays 29: 987-1000.

Leclerque A. (2008). Reorganization and monophyly of the genus Rickettsiella: all in good time. Appl Environ Microbiol 74: 5263-5264.

Leedale GF, Vickerman K. (2000). Phylum Euglenozoa. In: Lee JJ, Leedale GF, Bradbury P (eds). The Illustrated Guide to the Protozoa 2 edn Society of Protozoologists: Lawrence, pp 1135-1185.

Loy A, Arnold R, Tischler P, Rattei T, Wagner M, Horn M. (2008). probeCheck-a central resource for evaluating oligonucleotide probe coverage and specificity. Environ Microbiol 10: 2894-2898. 
Maddison DR, Maddison WP. (2001). MacClade 4: Analysis of Phylogeny and Character Evolution. Sinauer Associates Inc.: Sunderland, Massachusetts.

Moya A, Pereto J, Gil R, Latorre A. (2008). Learning how to live together: genomic insights into prokaryote-animal symbioses. Nat Rev Genet 9: 218-229.

Muhling M, Woolven-Allen J, Murrell JC, Joint I. (2008). Improved group-specific PCR primers for denaturing gradient gel electrophoresis analysis of the genetic diversity of complex microbial communities. ISME J 2: 379-392.

Murakami A, Miyashita H, Iseki M, Adachi K, Mimuro M. (2004). Chlorophyll $d$ in an epiphytic cyanobacterium of red algae. Science 303: 1633.

Nubel U, GarciaPichel F, Muyzer G. (1997). PCR primers to amplify 16S rRNA genes from cyanobacteria. Appl Environ Microbiol 63: 3327-3332.

Park DJ, Dastager SG, Lee JC, Yeo SH, Yoon JH, Kim CJ. (2007). Shimazuella kribbensis gen. nov., sp nov., a mesophilic representative of the family Thermoactinomycetaceae. Int J Syst Evol Micr 57: 2660-2664.

Pannebakker BA, Loppin B, Elemans CPH, Humblot L, Vavre F. (2007). Parasitic inhibition of cell death facilitates symbiosis. Proc Natl Acad Sci USA 104: 213-215.

Parniske M. (2000). Intracellular accommodation of microbes by plants: a common developmental program for symbiosis and disease? Curr Opin Plant Biol 3: $320-328$.

Pugh AL, Norton SA, Schauffler M, Jacobson GL, Kahl JS, Brutsaert WF et al. (1996). Interactions between peat and salt-contaminated runoff in Alton Bog, Maine, USA. J Hydrol 182: 83-104.

Rasolomampianina R, Bailly X, Fetiarison R, Rabevohitra R, Bena G, Ramaroson L et al. (2005). Nitrogen-fixing nodules from rose wood legume trees (Dalbergia spp.) endemic to Madagascar host seven different genera belonging to alpha- and beta-Proteobacteria. Mol Ecol 14: $4135-4146$.

Rodrigues JLM, Duffy MA, Tessier AJ, Ebert D, Mouton L, Schmidt TM. (2008). Phylogenetic characterization and prevalence of 'Spirobacillus cienkowskii,' a redpigmented, spiral-shaped bacterial pathogen of freshwater Daphnia species. Appl Environ Microbiol 74: 1575-1582.

Rydin H, Jeglum JK. (2006). The Biology of Peatlands. Oxford University Press Inc.: New York.

Schmitz-Esser S, Toenshoff ER, Haider S, Heinz E, Hoenninger VM, Wagner $M$ et al. (2008). Diversity of bacterial endosymbionts of environmental
Acanthamoeba isolates. Appl Environ Microbiol 74: 5822-5831.

Schnepf E, Schlegel I, Hepperle D. (2002). Petalomonas sphagnophila (Euglenophyta) and its endocytobiotic cyanobacteria: a unique form of symbiosis. Phycologia 41: 153-157.

Six C, Joubin L, Partensky F, Holtzendorff J, Garczarek L. (2007). UV-induced phycobilisome dismantling in the marine picocyanobacterium Synechococcus sp. WH8102. Photosynthesis Res 92: 75-86.

Swanson MS, Hammer BK. (2000). Legionella pneumophila pathogenesis: a fateful journey from amoebae to macrophages. Annu Rev Microbiol 54: 567-613.

Swofford DL. (2003). PAUP*. Phylogenetic Analysis Using Parsimony (*and Other Methods), 4.0 edn. Sinauer Associates Inc.: Sunderland, Massachusetts.

Turunen J, Tomppo E, Tolonen K, Reinikainen A. (2002). Estimating carbon accumulation rates of undrained mires in Finland-application to boreal and subarctic regions. Holocene 12: 69-80.

Wernegreen JJ. (2005). For better or worse: genomic consequences of intracellular mutualism and parasitism. Curr Opin Genet Dev 15: 572-583.

Werren JH, Baldo L, Clark ME. (2008). Wolbachia: master manipulators of invertebrate biology. Nat Rev Microbiol 6: 741-751.

Wieder RK, Vitt DH (eds) (2006). Boreal Peatland Ecosystems. Springer: Berlin.

Wolf E, Schussler A. (2005). Phycobiliprotein fluorescence of Nostoc punctiforme changes during the life cycle and chromatic adaptation: characterization by spectral confocal laser scanning microscopy and spectral unmixing. Plant Cell Environ 28: 480-491.

Yassin AF, Hupfer H, Klenk HP, Siering C. (2009). Desmospora activa gen. nov., sp nov., a thermoactinomycete isolated from sputum of a patient with suspected pulmonary tuberculosis, and emended description of the family Thermoactinomycetacea Matsuo et al. 2006. Int J Syst Evol Micr 59: 454-459.

Yoon JH, Kim IG, Shin YK, Park YH. (2005). Proposal of the genus Thermoactinomyces sensu stricto and three new genera, Laceyella, Thermoflavimicrobium and Seinonella, on the basis of phenotypic, phylogenetic and chemotaxonomic analyses. Int J Syst Evol Micr 55: 395-400.

Yubuki N, Edgcomb VP, Bernhard JM, Leander BS. (2009). Ultrastructure and molecular phylogeny of Calkinsia aureus: cellular identity of a novel clade of deep-sea euglenozoans with epibiotic bacteria. BMC Microbiol 9: 16 .

Supplementary Information accompanies the paper on The ISME Journal website (http://www.nature.com/ismej) 